TITLE:

\title{
Size-controlled in situ synthesis of metal-polymer nanocomposite films using a CO laser
}

\section{AUTHOR(S):}

Kashihara, Kazuhiko; Uto, Yuki; Nakajima, Takashi

\section{CITATION:}

Kashihara, Kazuhiko ...[et al]. Size-controlled in situ synthesis of metal-polymer nanocomposite films using a CO laser Polymer Bulletin 2021, 78: 6969-6981

ISSUE DATE:

2021

URL:

http://hdl.handle.net/2433/265477

\section{RIGHT:}

This is a post-peer-review, pre-copyedit version of an article published in 'Polymer Bulletin'. The final authenticated version is available online at: https://doi.org/10.1007/s00289-020-03481-0.; The full-text file will be made open to the public on 13 November 2021 in accordance with publisher's 'Terms and Conditions for Self-Archiving'.; This is not the published version. Please cite only the published version. この論文は出版社版でありません。引用の際には出版社版を

ご確認ご利用ください。 


\title{
Size-controlled in-situ synthesis of metal-polymer nanocomposite films
}

\section{using a $\mathrm{CO}_{2}$ laser}

\author{
Kazuhiko Kashihara · Yuki Uto · Takashi Nakajima* \\ Institute of Advanced Energy, Kyoto University, Gokasho, Uji, Kyoto 611-0011, Japan
}

\begin{abstract}
In-situ synthesis of metal-polymer nanocomposite films by irradiating a $\mathrm{CO}_{2}$ laser for several seconds is a new alternative to fabricate metal-polymer nanocomposite films. The main features of this method are that the number density of the synthesized metal nanoparticles is very high so that the optical density easily exceeds $0.5 \sim 1.5$ for the film thickness of $\sim 200 \mathrm{~nm}$, and owing to the short fabrication time and the use of non-focused laser beam, largescale processing is possible. For this technique to be applicable for a variety of purposes an important question is how and how much we can control the film properties. In this work we demonstrate that the size and size distribution of metallic nanoparticles in the synthesized nanocomposite films can be well-controlled by the choice of the laser power and irradiation time as well as the concentrations of nanoparticle precursor. Properties of the synthesized films can be roughly understood by considering the diffusion of metallic ions, atoms, and nanoparticles in the polymer film under the elevated temperature induced by the $\mathrm{CO}_{2}$ laser.
\end{abstract}

\section{Keywords}

silver nanoparticles; morphology; polyvinyl alcohol; nanocomposites; laser

*E-mail address: nakajima@iae.kyoto-u.ac.jp (Takashi Nakajima)

ORCID iD: https://orcid.org/0000-0003-4136-5383 


\section{Introduction}

Nanocomposites are materials with nanometer-size materials (filler) in another material (matrix), and they are used for a variety of applications such as sensors, optics, electronics, catalysis, reinforced materials, etc. A class of nanocomposites consist of metallic nanoparticles (NPs) as a filler in a polymer matrix, and they are conveniently used for many applications [1-5].

In-situ synthesis of metal-polymer nanocomposite films have some advantages over the ex-situ one in terms of the uniformity of synthesized nanoparticles in the polymer matrix. The well-known techniques for the in-situ synthesis are the direct dispersion [6], chemical reduction [7, 8], photo reduction [9-13], microwave reduction [14], and thermal reduction [15-18]. Chemical reduction method is sometimes combined with a post-processing such as laser-irradiation [19] to alter the film property. Recently we have developed another alternative [20] for the in-situ synthesis of nanocomposite films. Our method utilizes a non-focused $\mathrm{CO}_{2}$ laser beam to irradiate a polymer film (polyvinyl alcohol, PVA or polyethylene glycol, $\mathrm{PEG})$ which contains a precursor $\left(\mathrm{AgNO}_{3}\right)$ of $\mathrm{Ag}$ nanoparticles. In this technique the $\mathrm{CO}_{2}$ laser heats the substrate to promote the reduction of $\mathrm{Ag}$ ions in the polymer matrix on it. The advantage of our method is that the reduction speed is fast (from several seconds to a few tens of seconds) and no additional reducing agent is needed, since the polymer matrix itself serves as a reducing and stabilizing agent. Moreover, unlike the known photoreduction using a UV laser which requires the use of a well-focused laser beam down to a few tens of micron to speed up the reduction process, a very modest laser power without a focus is sufficient for the $\mathrm{CO}_{2}$ laser reduction, and hence the large-area processing is possible. More recently we have applied the developed technique to synthesize silver-methylcellulose films to study the influence of polymer molecular weight on film properties [21]. Substrate heating with a $\mathrm{CO}_{2}$ laser is a versatile method to fabricate functional films, and it can be used not only to promote the reduction speed of metallic ions dispersed in a polymer matrix (so-called metal-polymer nanocomposite films) but also to induce solid-state dewetting of metallic films (socalled nanostructured metallic films). Indeed, we have recently shown that the irradiation of a non-focused $\mathrm{CO}_{2}$ laser beam onto thin metallic films for a few tens of seconds at a few $\mathrm{W}$ enables us to rapidly induce nanostructures in thin $\mathrm{Au}$ [22] and Ag films [23] with some notable differences between them.

In this paper we study the morphological and optical properties of metal-polymer nanocomposite films by systematically varying the experimental parameters such as the $\mathrm{CO}_{2}$ laser power, irradiation time, and concentration of nanoparticle precursor to explore the possibility of size-controlled synthesis of metal-polymer nanocomposite 
films using a $\mathrm{CO}_{2}$ laser. As we will show later on in this paper, we have found that not only the laser power and irradiation time but also the concentration of nanoparticle precursor significantly influences the size and size distribution of nanoparticles, and accordingly the position and width of surface plasmon resonance. Related to this paper there are several works which report the control of size and number density of metal nanoparticles synthesized in the polymer matrix through chemical reduction [24], photoreduction [25, 26], and thermal reduction [27, 28]. Coevaporation of metal and polymer with separate evaporators brings a convenient flexibility to control the size and shape of nanoparticles [29-31]. Similarly, co-sputtering of metal and polymer can be used to achieve the controlled synthesis of nanocomposites [32, 33].

\section{Materials and methods}

\section{Materials}

PVA (molecular weight 60,000$)$ is purchased from Sigma-Aldrich, and silver nitrate $\left(\mathrm{AgNO}_{3}\right.$, purity $99.999 \%$ ) is purchased from Wako. All the chemicals are of reagent grade and used as purchased without any further purification.

\section{Laser}

For the synthesis of Ag-PVA films we employ a $\mathrm{CO}_{2}$ laser at $10.6 \mu \mathrm{m}$ (AL30P, Access Laser Co., peak power $60 \mathrm{~W}$, pulse duration $100-400 \mu \mathrm{s}$ depending on the laser power, repetition rate $2.5 \mathrm{kHz}$ ). Since the pulse duration is comparable to the pulse interval which is $400 \mu \mathrm{s}$, it is nearly in the quasi-CW mode. The $\mathrm{CO}_{2}$ laser power is measured with a power meter (Pronto-250, Gentec-EO Co.). The laser beam diameter is $\sim 10 \mathrm{~mm}$ at the position of the film with a Gaussian spatial profile. This means that the effective laser power density is different as a function of distance from the irradiation center [23]. Although it is technically possible to make the spatial profile of the laser beam to a nearly flat-top by introducing a commercial beam shaper we use the laser beam as it is in this work. Accordingly, all the data presented in this work have been taken at the irradiation center on the synthesized film where the laser power density is maximum.

\section{Synthesis of Ag-PVA films}

$0.125 \mathrm{~g}$ of PVA is mixed with $2 \mathrm{~mL}$ of highly purified and deionized water at room temperature under continuous stirring for $20 \mathrm{~min}$, and then it is heated to $95{ }^{\circ} \mathrm{C}$ for $45 \mathrm{~min}$ to completely dissolve PVA. After cooling down to the room temperature the PVA solution is mixed with a separately prepared solution which contains $0.04-0.16 \mathrm{~g}$ of silver nitrate and $1 \mathrm{~mL}$ of water. The above procedure results in the $\mathrm{AgNO}_{3}-\mathrm{PVA}$ solution which is composed of PVA (3.8 wt.\%), $\mathrm{AgNO}_{3}$ (1.2-4.9 wt.\%), and deionized water. The $\mathrm{AgNO}_{3}(1.2-4.9$ wt\%)-PVA solution is 
immediately spin-coated on a microscope cover glass (borosilicate glass, $18 \times 18 \times 0.15 \mathrm{~mm}$, Matsunami Co.) at 500 rpm for $5 \mathrm{sec}$ which is followed by $4000 \mathrm{rpm}$ for $10 \mathrm{sec}$. The $\mathrm{AgNO}_{3}-\mathrm{PVA}$ film is dried in air at room temperature for $30 \mathrm{~min}$, and then irradiated with the $\mathrm{CO}_{2}$ laser at the chosen laser powers and irradiation time.

\section{Characterization}

To characterize the synthesized Ag-PVA films, we employ a compact CCD spectrometer (USB2000+, Ocean Optics), and scanning electron microscope (SEM) (JSM-6500FE, JEOL) at $5 \mathrm{kV}$. For the analysis of the SEM images we employ the ImageJ software to obtain the size distribution of Ag NPs and the area fraction defined by [total surface area of NPs]/[total area of the SEM image], where the surface areas of the respective NPs are estimated by $\pi r^{2}$ with $r$ being the radius of NPs. Since the thickness of the synthesized films measured by the atomic force microscopy is about $200 \mathrm{~nm}$ (measured by atomic force microscope (VN-8010, Keyence)), there should be no clear difference between the Ag NPs at the surface of and in the PVA matrix, and accordingly the SEM images would well represent the morphology of the synthesized Ag NPs. In order to ensure that the surface morphology observed with the SEM originates from the formation of Ag NPs, we prepare a film from the pure PVA solution (without $\mathrm{AgNO}_{3}$ ), irradiate it with the $\mathrm{CO}_{2}$ laser at $1 \mathrm{~W}$ for $30 \mathrm{sec}$, and take the SEM image to find that the surface is very flat without any structures.

\section{Results and discussion}

\section{Film temperature}

Before showing the results of the films we first present the temporal variation of film temperature at the different laser powers. Since our $\mathrm{CO}_{2}$ laser is in the quasi-CW mode (i.e., pulse duration pulse interval), we can conveniently use a thermocouple with a small head $(\sim 1 \mathrm{~mm}$ diameter) to measure the film temperature at the irradiation center as a function of time [20, 22]. The results are presented in Fig. 1 at the laser powers of 0.4, 0.5, 0.6, 0.8 , and $1 \mathrm{~W}$ for the irradiation time of $2400 \mathrm{sec}$, respectively. The small temperature modulations arise from the fluctuation of the laser power. Upon laser irradiation the film temperature rapidly increases, and it reaches a nearly stead-state temperature in $30 \mathrm{sec}$ regardless of the incident laser power. Naturally, the steady-state temperature is higher for the higher laser power. When we turn off the laser, the film temperature rapidly cools down to the room temperature $\left(\sim 25^{\circ} \mathrm{C}\right)$. By recalling that the thickness of the glass substrate is $0.15 \mathrm{~mm}$ which is far thicker than the film itself, it is the glass substrate that mainly absorbs the $\mathrm{CO}_{2}$ laser energy, which indirectly heats the film on it. 


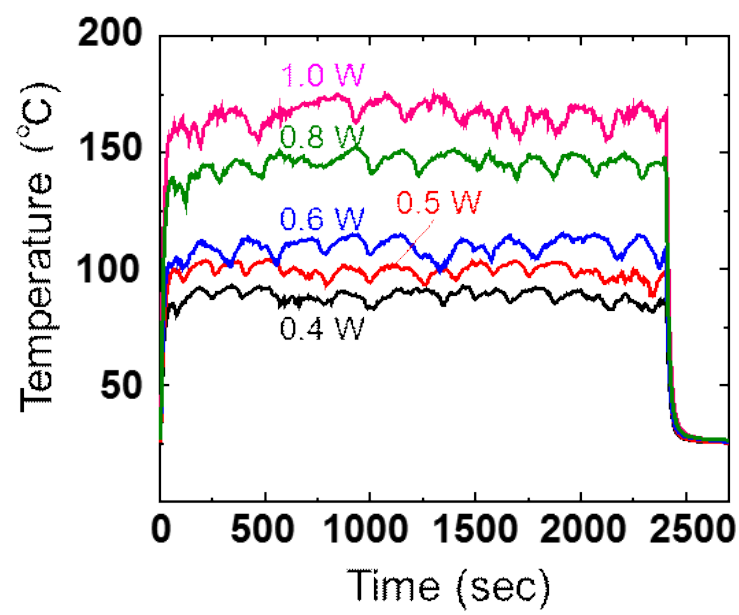

Fig. 1 Temperature change of the Ag-PVA film on a glass substrate as a function of time. In this measurement the laser power is $0.4,0.5,0.6,0.8,1 \mathrm{~W}$ and turned on and off at 0 and $2400 \mathrm{sec}$, respectively.

Since the boiling and thermal decomposition temperatures of bulk PVA are about 230 and $300{ }^{\circ} \mathrm{C}$, respectively, we can say that $0.4-1 \mathrm{~W}$ is the appropriate range of $\mathrm{CO}_{2}$ laser power.

\section{Effect of the concentration of nanoparticle precursor}

To start with, we study the influence of the concentration of nanoparticle precursor, i.e., $\mathrm{AgNO}_{3}$, in the $\mathrm{AgNO}_{3}$-PVA solutions to prepare the $\mathrm{AgNO}_{3}$-PVA films. Those $\mathrm{AgNO}_{3}-\mathrm{PVA}$ films are irradiated by the $\mathrm{CO}_{2}$ laser at $1 \mathrm{~W}$ for 10$1200 \mathrm{sec}$. The UV-vis spectra of the synthesized Ag-PVA films are shown in Fig. 2. For the irradiation time of 10 sec the peaks of the surface plasmon resonance (SPR) are located at about $405 \mathrm{~nm}$ for all the concentrations of 1.2, 2.4, and $4.9 \mathrm{wt} . \%$, and it is clear that Ag NPs have been formed in the PVA matrix in a much shorter time compared with the photoreduction method with a UV laser [10]. For the longer irradiation times of 120 and $1200 \mathrm{sec}$, the peaks of SPR shift to the longer wavelength side with a lift-up of the tail and the widths of the SPRs increases for all three concentrations. The shift of the peak of SPR to the longer wavelength side and the lift-up of its tail after the longer irradiation time imply the particle size increase and aggregation, respectively, while the increase of the its width means the broadened particle size distribution. This is qualitatively reasonable, since the mobilities of silver ions/ atoms/clusters/nanoparticles are higher in the heated (and hence softened) polymer matrix during the $\mathrm{CO}_{2}$ laser irradiation at $1 \mathrm{~W}$ (Fig. 1), and under such situation they are more likely to meet other silver ions/atoms/clusters/nanoparticles to form larger nanoparticles through the growth or aggregation. Furthermore, for a 
given irradiation time the height of the SPR is higher for the Ag-PVA films synthesized from the $\mathrm{AgNO}_{3}$-PVA solutions with higher concentration of $\mathrm{AgNO}_{3}$, and this obviously indicates that more Ag NP have been produced.
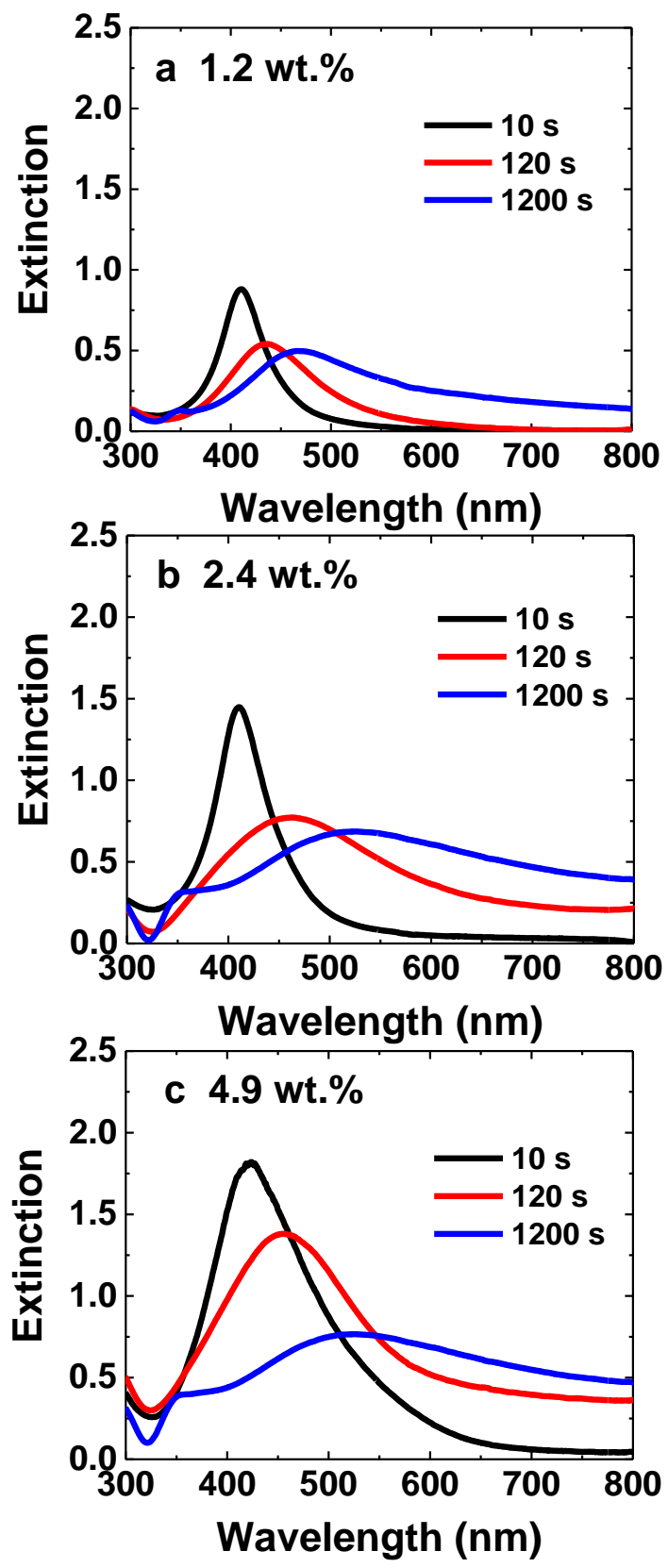

Fig. 2 UV-Vis spectra of the $\mathrm{Ag}\left(1.2,2.4\right.$, and 4.9 wt.\%)-PVA films synthesized from the $\mathrm{AgNO}_{3}-\mathrm{PVA}$ solutions with different concentrations of $\mathrm{AgNO}_{3}$, (a) $1.2 \mathrm{wt} . \%$, (b) $2.4 \mathrm{wt} . \%$, (c) $4.9 \mathrm{wt} . \%$. The laser power is $1 \mathrm{~W}$ for all cases. 


\section{Effect of the laser irradiation time}

We now fix the concentration of $\mathrm{AgNO}_{3}$ in the solution to $4.9 \mathrm{wt} \%$, and study the effect of the laser irradiation time on the film properties. The employed laser power is $1 \mathrm{~W}$ and the results are summarized in Fig. 3. From Fig. 3a we notice that, although a clear SPR of Ag NPs is observed for the irradiation time of $10 \mathrm{~s}$ it is broadened after the 120 sec irradiation (Fig. 2c), and then the distortion becomes more severe after the irradiation times of 1200 and 2400 sec (Fig. 3a). This change implies that significant aggregation of Ag NPs takes place in the heated (and hence softened) polymer matrix during the longer irradiation time at $1 \mathrm{~W}$, and this interpretation is confirmed by the SEM images shown in Figs. 3b-d. Using ImageJ we carry out the analysis of the SEM images, and obtain the size
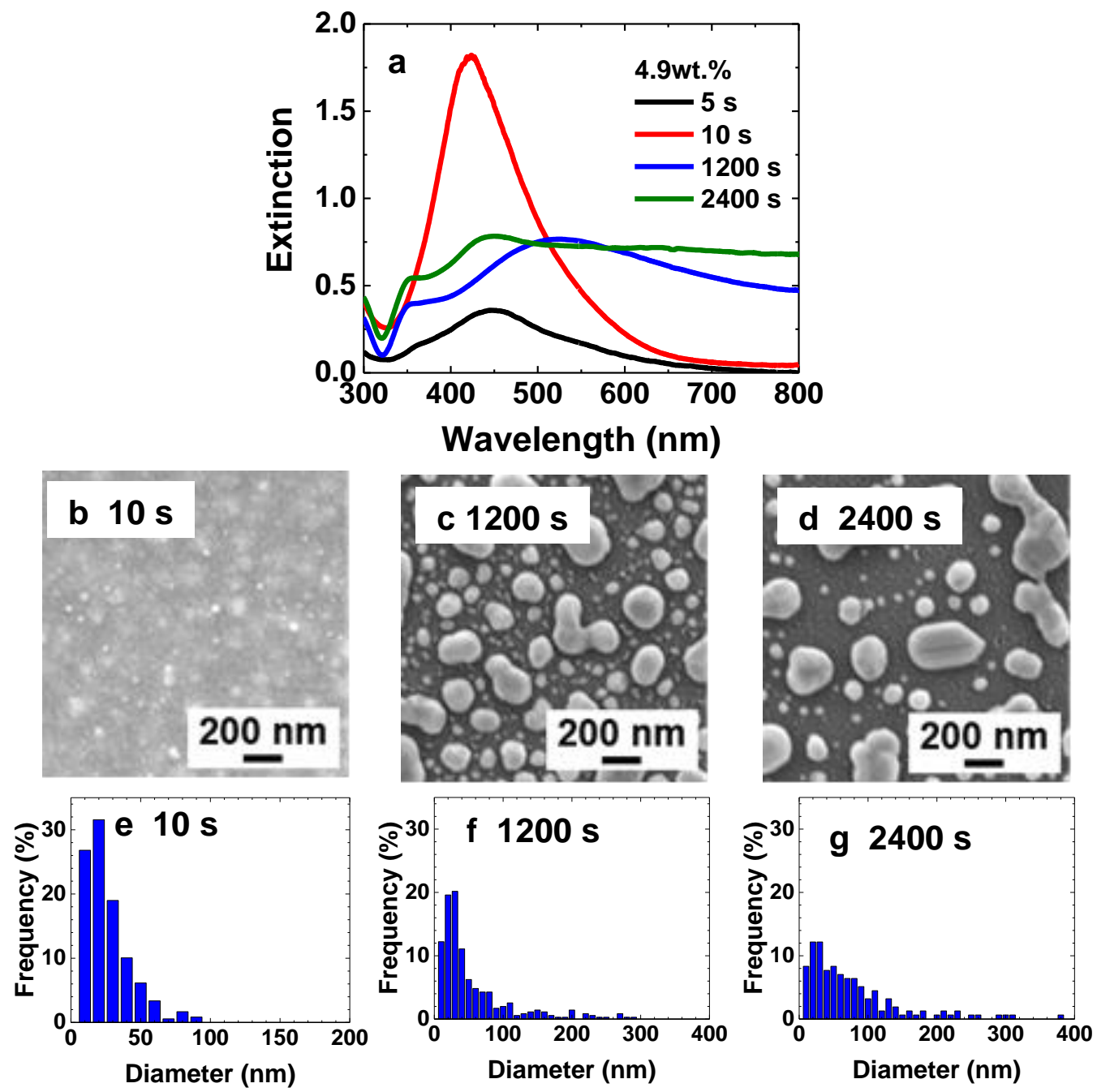

Fig. 3 (a) UV-Vis spectra, (b-d) SEM images, (e-g) histograms of nanoparticle size distribution of the $\mathrm{Ag}(4.9 \mathrm{wt} . \%)$-PVA films for different irradiation times (5 2400 s) at the laser power of $1 \mathrm{~W}$. 
distributions of Ag NPs after the irradiation times of 10, 1200, and $2400 \mathrm{sec}$, which are shown in Figs. 3e-g, respectively. The size of Ag NPs is relatively small and the size distribution is reasonably uniform for the irradiation time of $10 \mathrm{sec}$ (Fig. 3b and e). However, for the longer irradiation times the size becomes larger and the size distribution becomes less uniform, as shown in Figs. 3c-d and Figs. 3f-g. Note that the SEM images and the size distributions in Fig. 3c, f and Fig. 3d, g, respectively, do not seem to be consistent at first glance. This is simply because a large Ag NP occupies more space in the SEM images while it is counted as one in the distribution histogram, and they are actually consistent. The most interesting feature of Fig. 3 is that the progressive change of the optical as well as morphological properties of Ag NPs synthesized at the laser power of $1 \mathrm{~W}$ does not seem to terminate at least until the irradiation time of $2400 \mathrm{sec}$. Presumably this is because the film temperature is sufficiently high during the laser irradiation at $1 \mathrm{~W}$, and accordingly in the softened polymer matrix Ag NPs have a higher mobility to diffuse sufficient distance to meet others to aggregate.

To highlight the influence of laser power we synthesize the Ag-PVA films at the laser power of $0.5 \mathrm{~W}$ so that the film temperature stays below $100{ }^{\circ} \mathrm{C}$ (see Fig. 1), which means the much lower mobility of silver ions/atoms/clusters/nanoparticles in the polymer matrix at $0.5 \mathrm{~W}$ compared with that at $1 \mathrm{~W}$. The results are summarized in Fig. 4. From the UV-vis spectra shown in Fig. 4a we notice that the peak height of SPR grows during the irradiation of first few hundred sec some blue shift [15], while it hardly changes after the $1200 \mathrm{sec}$ irradiation. The SEM images and the histograms of NP size distribution shown in Figs. 4b-d and Figs. 4e-g, respectively, are consistent with the UV-vis spectra. The results at the laser power $0.5 \mathrm{~W}$ (Fig. 4) are in contrast to those at the laser power of $1 \mathrm{~W}$ (Fig. 3). This is because fewer Ag NPs are synthesized at $0.5 \mathrm{~W}$, and moreover, those fewer Ag NPs can diffuse for shorter distance in the less softened polymer matrix at $0.5 \mathrm{~W}$ (Fig. 1), as a result of which the Ag NPs synthesized under the $0.5 \mathrm{~W}$ laser power hardly suffer from aggregation even during the long irradiation time. It may be interesting to investigate how the reduction, diffusion, and aggregation of NPs go when the precursor of NP is replaced from $\mathrm{Ag}$ (AgNO3 in this work) to $\mathrm{Au}$ (say, $\mathrm{HAuCl} 4$ ), since the formation dynamics of $\mathrm{Ag}$ and $\mathrm{Au}$ NPs have been found somehow different [34]. 

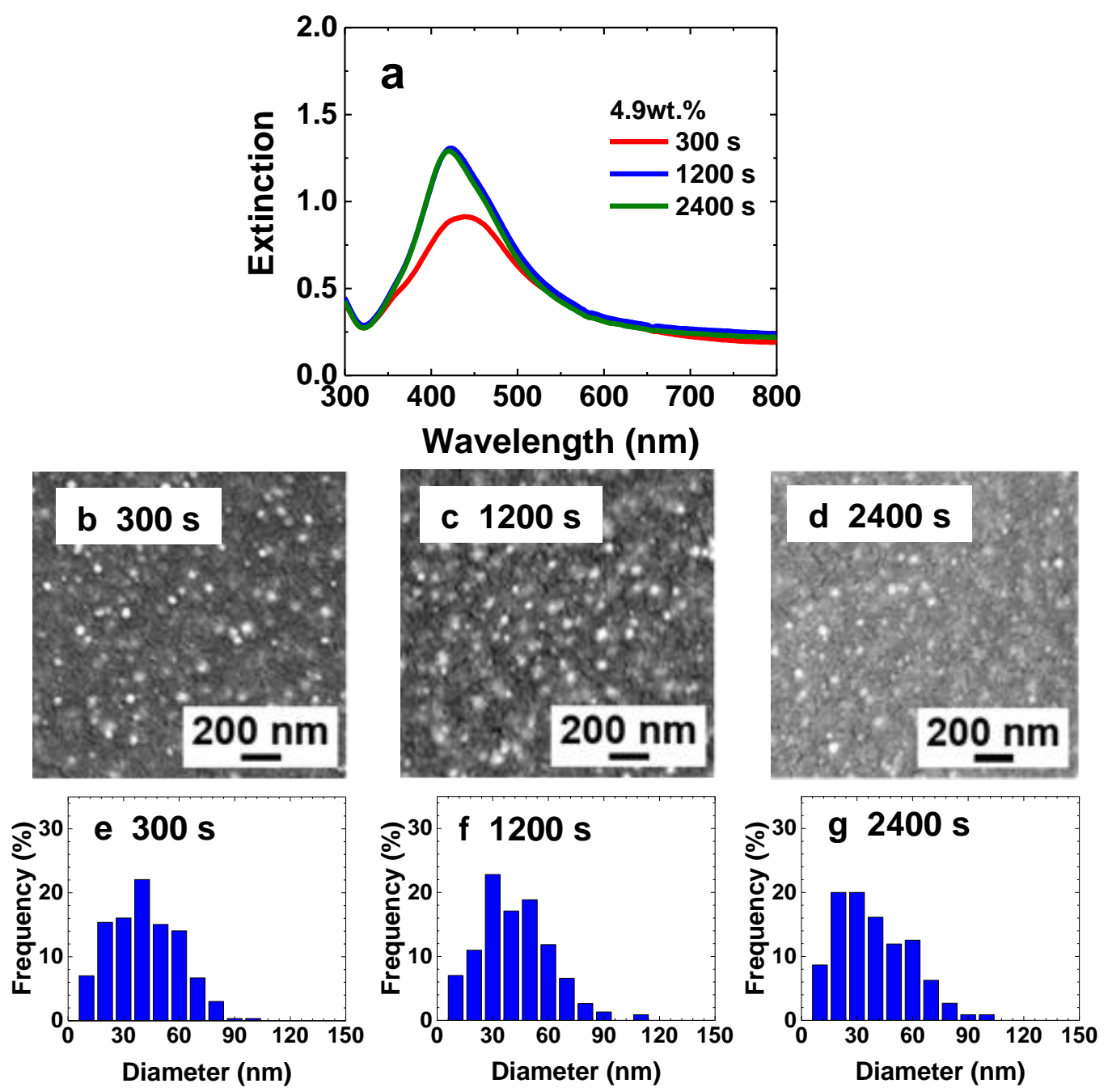

Fig. 4 Similar to Fig. 3 but at the laser power of $0.5 \mathrm{~W}$.

\section{Strategy to produce small and homogeneous Ag NPs}

From the above results, we have learned that the laser power and irradiation time as well as the concentration of NP precursor $\left(\mathrm{AgNO}_{3}\right)$ strongly influence the size and shape of $\mathrm{Ag} \mathrm{NPs}$ synthesized in the polymer matrix during $\mathrm{CO}_{2}$ laser irradiation. To synthesize smaller and more uniform Ag NPs in the polymer matrix, the $0.5 \mathrm{~W}$ laser power seems to be safer than the $1 \mathrm{~W}$ laser power, since the use of $0.5 \mathrm{~W}$ laser power restricts the diffusion of $\mathrm{Ag}$ NPs in the polymer matrix to synthesize more uniform Ag NPs (Fig. 4), while a precise control of irradiation time is crucial under the $1 \mathrm{~W}$ laser power to synthesize small Ag NPs with minimum aggregation (Fig. 3). Moreover, we can infer from Fig. 2 that the use of lower concentration (1.2 wt $\%$ ) of NPs precursor, i.e., $\mathrm{AgNO}_{3}$ in our case, is also beneficial to synthesize small Ag NPs with minimum aggregation. Knowing all the above, we prepare the $\mathrm{AgNO}_{3}$ - 

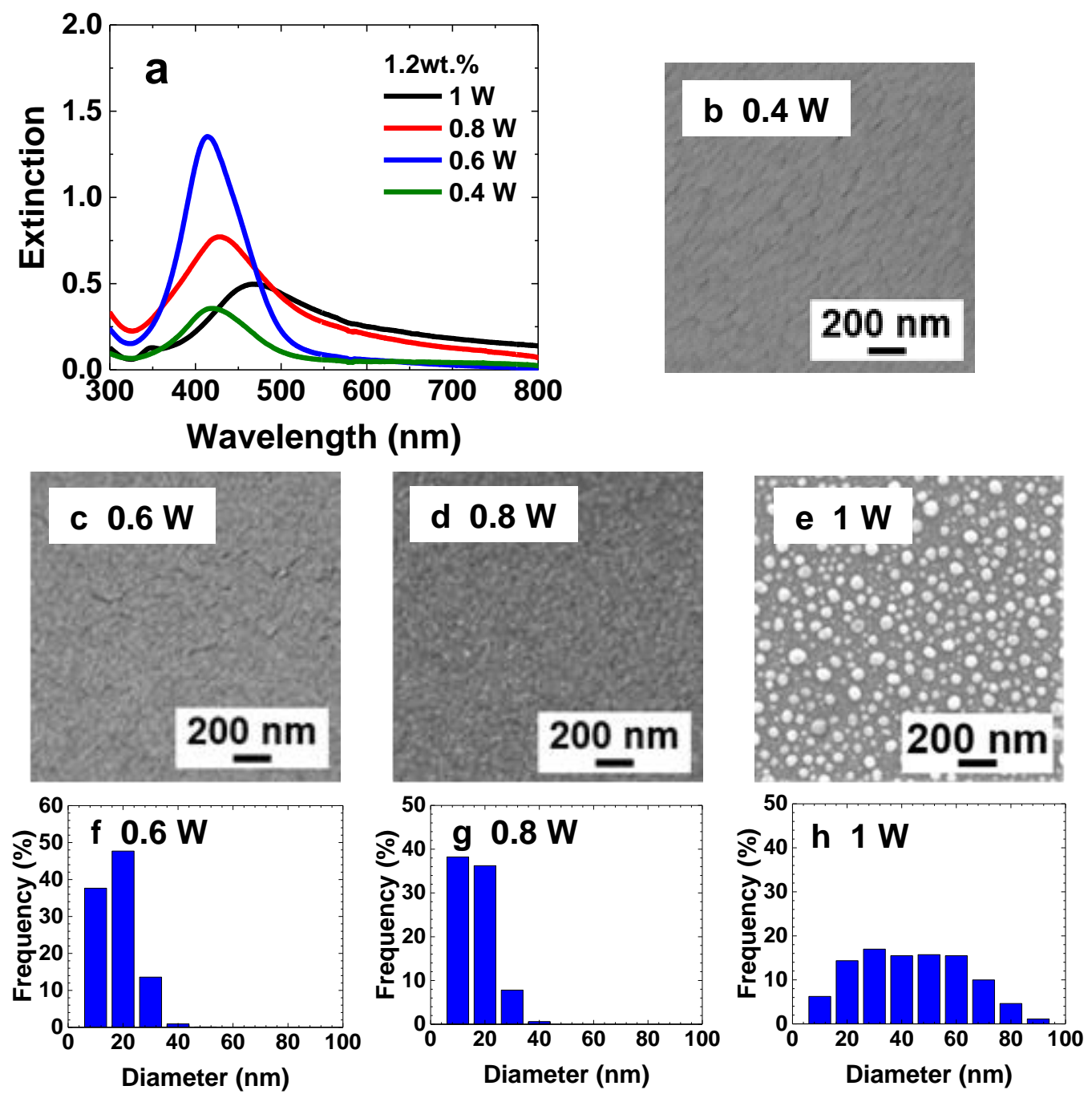

Fig. 5 (a) UV-Vis spectra, (b-e) SEM images, (f-h) histograms of nanoparticle size distribution of the $\operatorname{Ag}(1.2$ wt.\%)-PVA films for different laser powers. The irradiation time is $1200 \mathrm{sec}$ for all cases.

PVA solution with more diluted $1.2 \mathrm{wt} \%$ concentration of $\mathrm{AgNO}_{3}$, and synthesize the $\mathrm{Ag}(1.2 \mathrm{wt} \%)-\mathrm{PVA}$ films by the $1200 \mathrm{sec}$ irradiation at the relatively low laser power, $0.4-0.8 \mathrm{~W}$. The results are summarized in Fig. 5. Although we can observe the small peak of SPR at the laser power of $0.4 \mathrm{~W}$ (Fig. 5a), Ag NPs are not visible in the SEM image (Fig. 5b), which means that the synthesized Ag NPs are too small to detect with the resolution of our SEM. The reason for this would be that, due to the low film temperature of $80^{\circ} \mathrm{C}$ at $0.4 \mathrm{~W}$ (Fig. 1), the synthesized seed Ag NPs cannot diffuse even for a short distance to meet other seed Ag NPs to merge to form larger Ag NPs. As the laser power increases the size of Ag NPs grows (Figs. 5c-h) and the SPR becomes broader (Fig. 5a) with some red shift, which resembles the case of conventional thermal annealing [17] and CW laser annealing with a visible laser 
[35]. Under the same irradiation condition of $1200 \mathrm{sec}$ at $1 \mathrm{~W}$, the degree of aggregation of the $\operatorname{Ag}(1.2 \mathrm{wt} . \%)-\mathrm{PVA}$ film (Fig. 5a, e, h) is much less compared with that of the $\mathrm{Ag}(4.9$ wt.\%)-PVA film (Fig. 3a, c, f), because the number of AgNPs in the former film is much less to aggregate. Consistently, at the lower laser power of 0.4 and 0.6 $\mathrm{W}$, the synthesized $\mathrm{Ag}(1.2 \mathrm{wt} . \%)$-PVA films after the $1200 \mathrm{sec}$ irradiation at 0.4 and $0.6 \mathrm{~W}$ are practically free from aggregation, which is obvious from the absence of the tails in the corresponding SPR spectra (green and blue curves in Fig. 5a).

Now, we choose the laser power of $0.5 \mathrm{~W}$ with the irradiation time of $10-1200 \mathrm{sec}$, and synthesize the $\operatorname{Ag}(1.2$, 2.4, and 4.9 wt.\%)-PVA films. The UV-vis spectra of the synthesized $\operatorname{Ag}(1.2,2.4$, and 4.9 wt.\%)-PVA films are shown in Fig. 6. Unlike the $\operatorname{Ag}(1.2,2.4$, and 4.9 wt.\%)-PVA films synthesized at the laser power of $1 \mathrm{~W}$ (Fig. 2) the $10 \mathrm{sec}$ irradiation at $0.5 \mathrm{~W}$ does not result in the visible SPR in the UV-vis spectra for all three concentrations (Figs. 6a-c), because the reduction goes very slow at this laser power and hence film temperature. Of course, after the longer irradiation, say, $120 \mathrm{sec}$, the SPR becomes visible at all concentrations. Although Fig. 4 has already shown that aggregation of Ag NPs can be effectively avoided at the laser power of $0.5 \mathrm{~W}$ for the concentration of $4.9 \mathrm{wt} . \%$ (and obviously below 4.9 wt.\% as well), this does not necessarily mean that the size of synthesized Ag NPs under this condition are uniform, since the widths of SPRs we see in Figs. 6a-c are not very narrow. In contrast, the widths of SPRs we see in Figs. 2a-b after the $10 \mathrm{sec}$ irradiation at $1 \mathrm{~W}$ are narrower for all three concentrations of $\mathrm{AgNO}_{3}$. From the results at $1 \mathrm{~W}$ (Fig. 2) and $0.5 \mathrm{~W}$ (Fig. 6) with three different concentrations of $\mathrm{AgNO}_{3}$ we can confirm that not only the laser power and irradiation time but also the concentration of NPs precursor $\left(\mathrm{AgNO}_{3}\right.$ in this study) strongly influence the size and size distribution (and hence the peak position and width of SPR) of synthesized NPs in the polymer matrix. The use of digestive ripening process [36] may be one way, if necessary, to improve the dispersity of size distribution. 

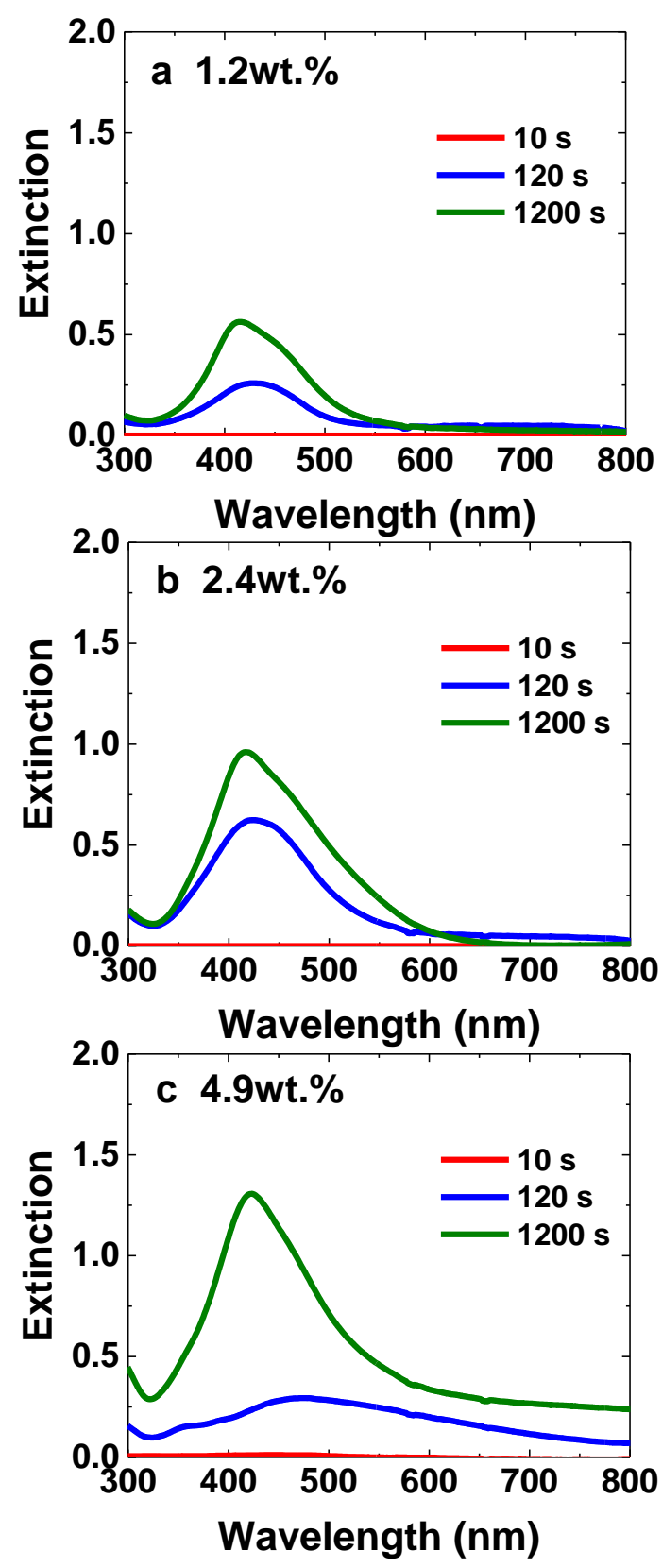

Fig. 6 Similar to Fig. 2 but at the laser power of $0.5 \mathrm{~W}$. 


\section{Conclusion}

In conclusion we have studied the optical and morphological properties of metal-polymer (Ag-PVA) nanocmposite films synthesized by the irradiation of $\mathrm{CO}_{2}$ laser with the laser power, irradiation time, and concentration of nanoparticle precursor being the controlled parameters. We have found that all those three factors influence the nanoparticle size and size distribution, and accordingly the position and width of surface plasmon resonance. The use of high laser power is very convenient to quickly (within a few seconds) synthesize nanoparticles in the polymer matrix, but the irradiation time and the concentration of nanoparticle precursor have to be carefully chosen. Otherwise severe aggregation can take place. We have found two approaches to synthesize relatively small metal NPs without severe aggregation. One is to set the laser power low and the other is to employ the low concentration of nanoparticle precursor. Our findings indicate that the size and size distribution of metal nanoparticles can be wellcontrolled by the choice of $\mathrm{CO}_{2}$ laser power, irradiation time, and concentration of nanoparticle precursor.

\section{Acknowledgements}

This work was supported by a Grant-in-Aid for scientific research from the Ministry of Education, Culture, Sports, Science and Technology (Japan). 


\section{References}

1. Sih BC, Wolf MO (2005) Metal nanoparticle - Conjugated polymer nanocomposites. Chem Commun 33753384. https://doi.org/10.1039/b501448d

2. Jain PK, Huang X, El-sayed IH, El-sayed MA (2008) Noble Metals on the Nanoscale: Optical and Photothermal Properties and Some Applications. Acc Chem Res 41:7-9. https://doi.org/10.1021/ar7002804

3. Ramesh G V., Porel S, Radhakrishnan TP (2009) Polymer thin films embedded with in situ grown metal nanoparticles. Chem Soc Rev 38:2646-2656. https://doi.org/10.1039/b815242j

4. Faupel F, Zaporojtchenko V, Strunskus T, Elbahri M (2010) Metal-polymer nanocomposites for functional applications. Adv Eng Mater 12:1177-1190. https://doi.org/10.1002/adem.201000231

5. Mir SH, Nagahara LA, Thundat T, et al (2018) Review-Organic-Inorganic Hybrid Functional Materials: An Integrated Platform for Applied Technologies. J Electrochem Soc 165:B3137-B3156. https://doi.org/10.1149/2.0191808jes

6. Mbhele ZH, Salemane MG, Sittert CGCE Van, et al (2003) Fabrication and Characterization of Silver Polyvinyl Alcohol Nanocomposites. Chem Mater 15:5019-5024

7. Khanna PK, Singh N, Charan S, et al (2005) Synthesis and characterization of Ag/PVA nanocomposite by chemical reduction method. Mater Chem 93:117-121. https://doi.org/10.1016/j.matchemphys.2005.02.029

8. Xu P, Han X, Zhang B, et al (2014) Multifunctional polymer-metal nanocomposites via direct chemical reduction by conjugated polymers. Chem Soc Rev 43:1349-1360. https://doi.org/10.1039/c3cs60380f

9. Korchev AS, Bozack MJ, Slaten BL, Mills G (2004) Polymer-Initiated Photogeneration of Silver Nanoparticles in SPEEK/PVA Films: Direct Metal Photopatterning. J Am Chem Soc 126:10-11. https://doi.org/10.1021/ja037933q

10. Sakamoto M, Tachikawa T, Fujitsuka M, Majima T (2006) Acceleration of Laser-Induced Formation of 
Gold Nanoparticles in a Poly ( vinyl alcohol ) Film. Langmuir 22:6361-6366

11. Pucci A, Bernabò M, Elvati P, et al (2006) Photoinduced formation of gold nanoparticles into vinyl alcohol based polymers. J Mater Chem 16:1058-1066. https://doi.org/10.1039/b511198f

12. Sakamoto M, Tachikawa T, Fujitsuka M, Majima T (2007) Photochemical formation of Au/Cu bimetallic nanoparticles with different shapes and sizes in a poly(vinyl alcohol) film. Adv Funct Mater 17:857-862. https://doi.org/10.1002/adfm.200600700

13. Lee CJ, Karim MR, Lee MS (2007) Synthesis and characterization of silver/thiophene nanocomposites by UV-irradiation method. Mater Lett 61:2675-2678. https://doi.org/10.1016/j.matlet.2006.10.021

14. Jiang T, Li J, Zhang L, et al (2014) Microwave assisted in situ synthesis of Ag-NaCMC films and their reproducible surface-enhanced Raman scattering signals. J Alloys Compd 602:94-100

15. Porel S, Singh S, Harsha SS, et al (2005) Nanoparticle-embedded polymer: In situ synthesis, free-standing films with highly monodisperse silver nanoparticles and optical limiting. Chem Mater 17:9-12. https://doi.org/10.1021/cm0485963

16. Karthikeyan B, Anija M, Phillip R (2006) In situ synthesis and nonlinear optical properties of Au:Ag nanocomposite polymer films. Appl Phys Lett 88:053104. https://doi.org/10.1063/1.2168667

17. Gradess R, Abargues R, Habbou A, et al (2009) Localized surface plasmon resonance sensor based on AgPVA nanocomposite thin films. J Mater Chem 19:9233-9240. https://doi.org/10.1039/b910020b

18. Hariprasad E, Radhakrishnan TP (2013) In situ fabricated polymer-silver nanocomposite thin film as an inexpensive and efficient substrate for surface-enhanced raman scattering. Langmuir 29:13050-13057. https://doi.org/10.1021/la402594j

19. Elashmawi IS, Menazea AA (2019) Different time' s Nd : YAG laser-irradiated PVA / Ag nanocomposites : structural , optical , and electrical. J Mater Res Technol 8:1944-1951

20. Kashihara K, Uto Y, Nakajima T (2018) Rapid in situ synthesis of polymer-metal nanocomposite films in 
several seconds using a CO2 laser. Sci Rep 8:14719. https://doi.org/10.1038/s41598-018-33006-9

21. Nishikawa H, Nakata E, Nakano S, et al (2019) Influence of polymer molecular weight on the properties of in situ synthesized silver - methylcellulose nanocomposite films with a CO2 laser. J Mater Sci 55:20902100. https://doi.org/10.1007/s10853-019-04149-5

22. Maurya SK, Uto Y, Kashihara K, et al (2018) Rapid formation of nanostructures in Au films using a CO2 laser. Appl Surf Sci 427:961-965. https://doi.org/10.1016/j.apsusc.2017.09.044

23. Faniayeu I, Ishimatsu Y, Nakajima T (2019) Surface plasmon resonance tuning of Ag nanoisland films using a CO2 laser. J Phys D Appl Phys 52:1-8. https://doi.org/10.1088/1361-6463/ab1b7b

24. Chen C, Li J, Luo G, et al (2012) Size-controlled in situ synthesis and photo-responsive properties of silver/poly(methyl methacrylate) nanocomposite films with high silver content. Appl Surf Sci 258:1018010184. https://doi.org/10.1016/j.apsusc.2012.06.102

25. Abyaneh MK, Paramanik D, Varma S, et al (2007) Formation of gold nanoparticles in polymethylmethacrylate by UV irradiation. J Phys D Appl Phys 40:3771-3779. https://doi.org/10.1088/0022-3727/40/12/032

26. Spano F, Massaro A, Blasi L, et al (2012) In situ formation and size control of gold nanoparticles into chitosan for nanocomposite surfaces with tailored wettability. Langmuir 28:3911-3917. https://doi.org/10.1021/la203893h

27. Torrell M, Cunha L, Cavaleiro A, et al (2010) Functional and optical properties of Au:TiO 2 nanocomposite films: The influence of thermal annealing. Appl Surf Sci 256:6536-6542. https://doi.org/10.1016/j.apsusc.2010.04.043

28. Torrell M, Kabir R, Cunha L, et al (2011) Tuning of the surface plasmon resonance in TiO2/Au thin films grown by magnetron sputtering: The effect of thermal annealing. J Appl Phys 109:1-9. https://doi.org/10.1063/1.3565066 
29. Takele H, Greve H, Pochstein C, et al (2006) Plasmonic properties of Ag nanoclusters in various polymer matrices. Nanotechnology 17:3499-3505. https://doi.org/10.1088/0957-4484/17/14/023

30. Takele H, Jebril S, Strunskus T, et al (2008) Tuning of electrical and structural properties of metal-polymer nanocomposite films prepared by co-evaporation technique. Appl Phys A Mater Sci Process 92:345-350. https://doi.org/10.1007/s00339-008-4524-0

31. Beyene HT, Chakravadhanula VSK, Hanisch C, et al (2010) Preparation and plasmonic properties of polymer-based composites containing Ag-Au alloy nanoparticles produced by vapor phase co-deposition. $\mathrm{J}$ Mater Sci 45:5865-5871. https://doi.org/10.1007/s10853-010-4663-5

32. Schürmann U, Hartung W, Takele H, et al (2005) Controlled syntheses of Ag-polytetrafluoroethylene nanocomposite thin films by co-sputtering from two magnetron sources. Nanotechnology 16:1078-1082. https://doi.org/10.1088/0957-4484/16/8/014

33. Avasthi DK, Mishra YK, Kabiraj D, et al (2007) Synthesis of metal-polymer nanocomposite for optical applications. Nanotechnology 18:. https://doi.org/10.1088/0957-4484/18/12/125604

34. Hourd AC, Baker RT, Abdolvand A (2015) Structural characterisation of printable noble metal/poly(vinylalcohol) nanocomposites for optical applications. Nanoscale 7:13537-13546. https://doi.org/10.1039/c5nr03636d

35. Paeng D, Lee D, Grigoropoulos CP (2014) Characteristic time scales of coalescence of silver nanocomposite and nanoparticle films induced by continuous wave laser irradiation. Appl Phys Lett 105:1-5. https://doi.org/10.1063/1.4893465

36. Sahu P, Prasad BLV (2013) Fine control of nanoparticle sizes and size distributions: Temperature and ligand effects on the digestive ripening process. Nanoscale 5:1768-1771. https://doi.org/10.1039/c2nr32855k 